\title{
Research on the Innovation Model and Application of Human Resource Management Based on Big Data
}

\author{
Yuhuan CHENG \\ Wuhan Business University, Wuhan,430056, China \\ E-mail:7341346@qq.com
}

Key words: Innovation Model; Human Resource Management; Big Data

\begin{abstract}
Nowadays, informationization is the primary purpose of the development of various industries. It is crucial for enterprises seeking improvement to promote development by capitalizing on the storage and analysis capabilities of big data information, particularly human resources which require fresh management modes. Amid the environment of big data and through the analysis of the relationship between big data and human resource management, this paper: enumerates the four types of data that can constitute big data in the present-day human resource management; puts forward the innovation modes of recruitment, talent evaluation, decision-making and evidence-based management on the foundation of big data in the management process in accordance with the several problems in the current development of human resource management; And finally, expounds the economic and security issues that should be paid heed to in human resource management which integrates big data.
\end{abstract}

\section{Introduction}

This is an era of "big data", of the "big bang” of human resource information, and of the great revolution of human resource management. [1] In 1980, Alvin Toffler and others prophetically indicated that big data was drawing near. Gartner believed that big data was a sort of information asset that featured tremendous amount, high growth rate and diversity and that could possess mightier decision-making power, more acute insight and stronger capacity for optimizing procedures only if it acquired a fresh processing mode. From 2008 onwards, papers pertaining to big data have been published in succession in world-class authoritative journals. [2] For instance, Graham Rowe and others published Big data: The next Google in Nature, explicating the relationship between big data and Google as well as the development of big data; Dealing the Data was published in Science in 2011, elaborating on how data flow accelerates social advancement. Nowadays, informationization is the primary purpose of the development of various industries. It is crucial for enterprises seeking improvement to promote development by capitalizing on the storage and analysis capabilities of big data information, particularly human resources which require fresh management modes. [3] In recent years, with the evolution of the information network era, big data has become a hallmark of our times. The essence of big data represents the unprecedented revolution in the domains of thought, commerce and management. The colossal amount of information is in the process of being opted for or deleted holistically. [4] Thus it is noticeable that big data has already permeated every informationalized field of the modern world. In human resource management, big data gradually functions as quantification. What the human resource management system desperately needs to explore is how to accomplish the innovation of human resource management by dint of bid data.

\section{Problems in Human Resource Management}

\section{A. Unscientific Traditional Management Models}

Traditional management excludes humans' initiative and is indeed aimed at things. Thereupon, humans may become the auxiliary products of things and employees' activeness would be 
suppressed due to excessively stringent management and control. Rigid management modes reduce human resource management to inflexible model of business nature, obliterate humanity, and are unable to bring out employees' initiative and enterprises' dynamism. Eventually, the development of enterprises would be hampered and the supposed purposes of human resource management may not be achieved. [5] This traditional and rigid system is so entrenched that it seems against the grain in the current era of big data pursuing knowledge economy. Consequently, it is imperative to reform traditional modes, and how to capitalize on the big-data advantage of the internet to propel the reform is not only a major task for enterprises, but also a conundrum existing in the human resource reform.

\section{B. Managers' Threadbare and Backward Ideas}

The innovation of ideas is a significant characteristic of the big data reform. Nevertheless, in terms of the current situation of corporate development, some managers still cleave to trite ideas and are unable to discern the international climate confronting the enterprises. They stick to traditional notions of management, still believing that human resource management is nothing more than a regular management within the enterprise. [6] Thus they fail to connect human resource management to the external environment, unconscious that human labor has become a crucial decisive factor in the development of enterprises. If managers could not change their ideas, then it is difficult for them to reverse the traditional management modes and to prompt the transformation of human resource management. Therefore, for the modes of human resource management to really change, the transformation of managers' ideas must be expedited in order to facilitate their understanding of the opportunities and challenges confronting human resources in the times of big data, and thus to urge the managers to reform with keen determination.

\section{The Shortage of Talents}

Enterprises are scrambling for talents and the demand for talents for the sake of enterprises' development and expansion is also increasing. And the quality requirements for employees are raised. Nevertheless, with the traditional modes, enterprises recruit and train talents at a snail's pace and the revenue cycle prolongs, which do not conform to the high-speed trend of social development of the present day. [7] Thus, quite a few enterprises are short of talents, and they lack the momentum for development, both of which render the enterprises unable to realize further optimization. Whereas big data can speed up talent cultivation, recruitment and training by dint of information technology, in order to satisfy enterprises' demand for talents. To manage human resources by virtue of information technology can help effectively improve efficiency, recruit all manner of exceptional talents for enterprises' advancement, and in the meantime fuel social development. Accordingly, management in the times of bid data boasts more advantages.

\section{The Era of Big Data and the Necessity of Management Reform}

Big data, with the internet as the medium, boasts the characteristics of large volume, miscellaneous data and speedy processing. Its application has gradually permeated every nook and cranny of the society, controlling the convergence, diffusion and transmission of data worldwide. Under such circumstances, if enterprises could adapt to the situation, reform with keen determination, introduce internet big data and allow it to assist in the corporate management, then they are definitely able to improve efficiency and effectiveness, and usher in the fresh epoch of intelligence. Particularly in the field of human resource management, this is of great significance for the development of enterprises. [8 ] Transforming traditional modes and adapting to big data would give a mighty impetus to the improvement of enterprises' comprehensive strengths and competitiveness. Against the backdrop of economic globalization, that the internet eliminates the territorial effects internationalizes enterprises, but nonetheless renders management more herculean. Globalized data fusion, however, precisely addresses the problem, and enterprises are able to conduct management by dint of data base and thus to improve the efficiency of human resources. Thus, internet big data not only exerts pressure of renovation on enterprises, but also affords impetus of reform and prospects of interests. 


\section{The Innovative Management Models of Big Data in Human Resources}

The process of formulating strategies of human resource management needs to be based on big data. Firstly, the internal and external environment of human resources should be analyzed, and then the supply and demand of human resources should be predicted accordingly. In view of the abovementioned questions and necessity, the author will put forward four types of innovative modes of management in accordance with big data. The model of management is demonstrated in Diagram 1.

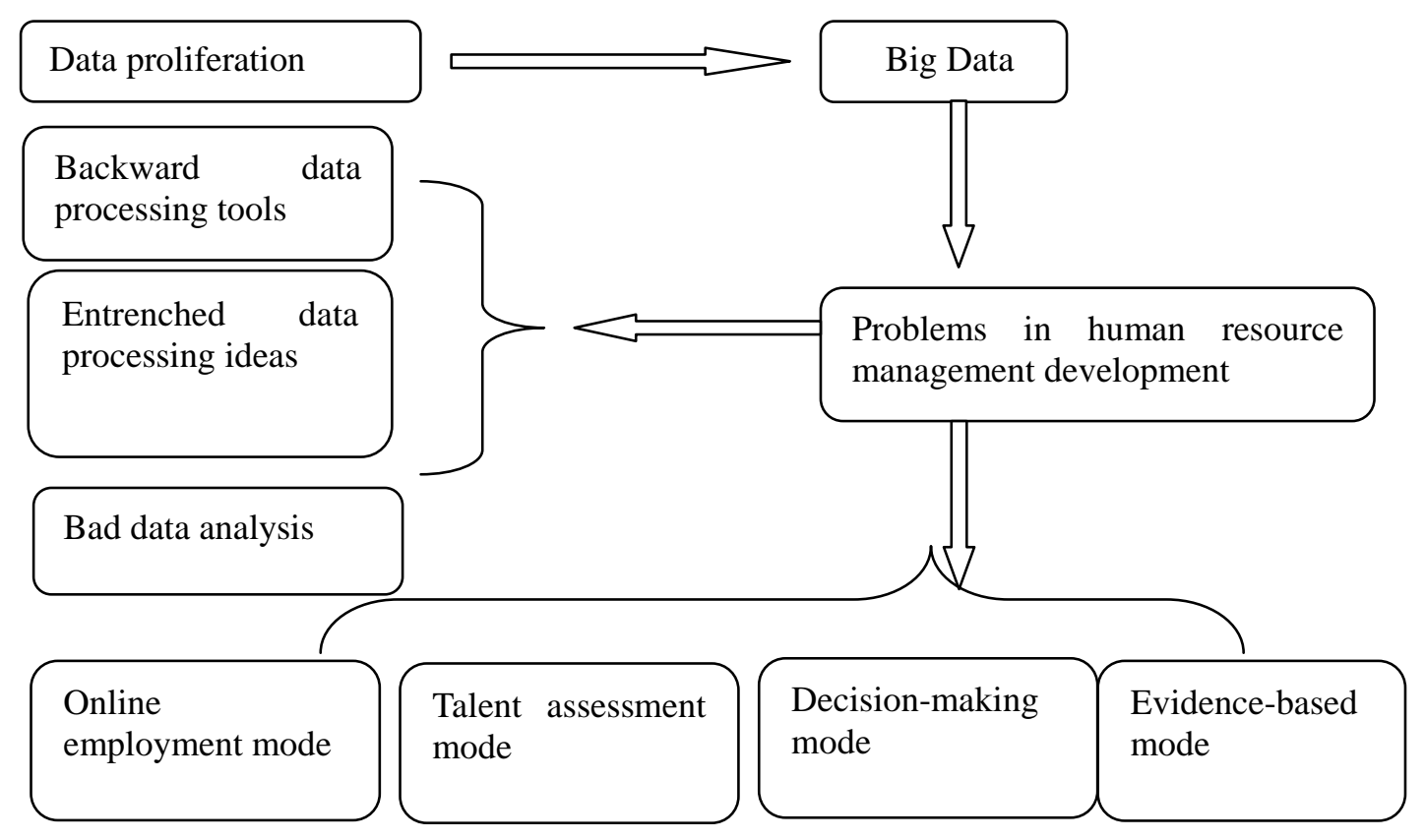

Diagram 1: the construction of the innovative model of human resource management based on big data

\section{A. The band-new mode of employment based on the social network}

Against the backdrop of the big data explosion, late-model employment is constantly incorporating the social network to become three-dimensional. And the relatively more successful social network is Linkedln which is able to employ social genes to compensate for the shortcomings of the traditional online one-way recruitment, both contributing to the deep mutual understanding between employers and employees, and helping save the cost of recruitment. It also consolidates the foundation of the "big data" analysis in recruitment in accordance with the status quo of the human resource data base. On the one hand, the departments can acquire the serial analysis outcomes regarding recruits and their tendencies of employment, which constitute solid foundation for future recruitment; on the other hand, enterprises can, by virtue of big data of the social network, procure directly the sundry information of employees, including their occupations, living conditions, social relationships, personal vocational abilities and so forth, in order to form the three-dimensional information of the candidates.

\section{B. The talent assessment mode under the big data processing technology}

Talent assessment is a specific technology in current human resource management, on which Human Resources Department has put a high premium. Currently, a majority of human resources departments still employ expert evaluation, comprehensive assessment, capability assessment and other assessment methods. However, these methods often render the assessment outcomes excessively subjective. Thus, big data technology helps improve on talent performance evaluation, and talent selection and classification; assists Human Resources Department in selecting talents more objectively by virtue of collecting subjects' assessment data, resorting to more reliable assessment indicators derived through more humane assessment methods, and employing visualized 
data analysis technology which includes tag cloud, history flow, spatial information flow and other elements to make the analysis outcomes graphical and fluid.

\section{The talent decision-making mode processed quantitatively}

In human resource strategy, management decision is the part that requires large quantities of book titles most. It is not only in control of current real-time conditions, but also able to make analysis for future trends of development. Traditional leader's decisions and support are more dependent on various personnel statistics and statements. From the perspective of techniques, $\mathrm{BI}$ (Business Intelligence) is employed as the primary approach to excavate and analyze human resource information. With the development of the big data technology, only through gathering more correct information resources of organizations and personnel and accomplishing the comprehensive correlation analysis of the organizations, posts, personnel and businesses within can the various talent decisions become data-supported and evidence-based.

\section{D.The evidence-based mode in human resource management}

The core of evidence-based human resource management consists in employing data, facts, analytical methods, scientific approaches, targeted evaluations and precise evaluative research or case study to uphold the suggestions, decisions, practices and conclusions proposed by oneself in terms of human resource management. The first one is human resource management audit. Audit activities can help identify current management conditions through organizers and understand how to rectify management functions. By virtue of information technology, enterprises can garner data sets comprising such complex elements as employment, performance evaluation and remuneration. And professionals will audit the data, compare the assessment outcomes of human resource management practices of this organization with the corresponding benchmarks, and report the audit outcomes to the top executives. The second one is the measuring indicator of human resource management and benchmarking. In the era of big data, the corporate information management systems can readily glean some basic financial index and non-financial index, compare these indices with some preset measuring indicators, identify the disparity between enterprise and the benchmark enterprises, and then make corresponding adjustments.

\section{Conclusion}

Through summarizing the existent problems in human resource management under current circumstances and integrating the big data concept into human resource management, this paper puts forward four types of innovative modes of management: the new mode of recruitment on the social networks, talent assessment mode, talent decision-making mode, and the evidence-based mode of human resource management. This paper also brings forward the idea that in the development of human resource management modes, big data constitutes both the opportunity and the perilous zone of destruction. In reforming human resource management, enterprises must control the dissemination of information, guard against the negative repercussions exerted by big data such as information leak and brain drain, maintain corporate strengths, guarantee the scientific nature and rigor of the internal information management of enterprises, and reinforce preventive measures.

\section{References}

[1] Norman M.Scarborough, Thomas W. 2000

[2] Angus Maddison,D.S.Prasada Rao and William F. . 2002

[3] Yan.Jun, "Contribution of leadership, attitudes, and behaviors to collective entrepreneurship: An empirical Study of United Stated small family businesses" DAI-A 62/05,p. . 2001

[4] Cooke, P,Roper, S,Wylie, P.The golden thread of innovation and Northern Ireland's evolving regional innovation system. Regional Studies . 2003

[5] Dahmén,E.Entrepreneurial activityand the development of Swedish industry. Development 
blocks’industrial economics . 1950

[6] Durlauf,S. N.Spillovers, stratification and inequality. European Economic Review. 1994

[7] Cervero,R.Transit-oriented development and joint development in the United States: a literature review. . 2002

[8] Charles, A. M de bartolome,,Stephen, L. Rose.Who’s in charge of the central city? The conflict between efficiency and equity in the design of a metropolitan areas. Journal of Urban Economics. 2004 